\title{
Subvenções federais dadas à agropecuária brasileira no período de 2003 a 2019
}

\author{
Federal subsidies given to Brazilian agriculture in the period from \\ 2003 to 2019
}

Felipe José Gurgel do Amaral ${ }^{1}$ (D), Carlos José Caetano Bacha ${ }^{1}$ (1)

'Programa de Pós-graduação em Economia Aplicada, Escola Superior de Agricultura "Luiz de Queiroz" (ESALQ), Universidade de São Paulo (USP), Piracicaba (SP), Brasil. E-mails: felipejosegurgeldoamaral@gmail.com; carlosbacha@usp.br

Como citar: Amaral, F. J. G., \& Bacha, C. J. C. (2023). Subvenções federais dadas à agropecuária brasileira no período de 2003 a 2019. Revista de Economia e Sociologia Rural, 61(1), e251646. https://doi.org/10.1590/1806-9479.2021.251646

Resumo: O Governo Federal, desde os anos de 1990, tem criado novos instrumentos para concessão de crédito rural, de preços mínimos e de seguro rural, mediante os quais ele concede subvenções à iniciativa privada para operar parcela dos mesmos. Essas subvenções estão regulamentadas pela Lei no 8.427 de 1992. O presente artigo tem como objetivo analisar a evolução das subvenções econômicas concedidas pelo Governo Federal à agropecuária do País no período de 2003 a 2019 por meio de uma pesquisa documenta e explicativa, empregando os métodos observacional, estatístico e interpretativo e fazendo uso de dados do Ministério da Economia. Constatou-se que: (1) o setor agropecuário reduziu a sua importância nas subvenções feitas pelo Governo Federal, passando de 9\% dessas subvenções em 2003 para 1,8\% em 2019; (2) a maior parte das subvenções federais destinadas à agropecuária é cedida a programas de crédito rural; (3) a concessão de equalização da taxa de juros ocorre a favor da agropecuária familiar nos últimos anos, ao passo que a concessão da equalização de preços privilegia a agropecuária não familiar. Essas alterações estão coerentes com a mudança da orientação da política agrícola desde meados dos anos de 1990.

Palavras-chave: política agrícola, subvenção econômica, crédito rural.

\begin{abstract}
The Federal Government has created new programs of rural credit, minimum price policy and rural insurance since 1990s that are partially run by private sector, which receives Federal subsidies (regulated by Law 8,427 issued in 1992). This paper aims to analyze the evolution of economic subsidies granted to agriculture in Brazil in the period from 2003 to 2019 through a documentary and explanatory research and making using of observational, statistical and interpretive methods to deal with Ministry of Economy's dataset. It was found that: (1st) the agricultural sector has reduced its share into the Federal Government's grants, declining from 9\% in 2003 to 1.8\% in 2019; (2) most federal subsidies for agriculture are granted to the Rural Credit Programs; (3) the granting of interest rate equalization has been in favor of family farming in recent years, while the granting of price equalization has favored non-family farming. These findings are coherent with the new private-backed support given to agricultural policy since the mid-1990.
\end{abstract}

Keywords: Agricultural policy, economic subsidies, rural credit.

\section{Introdução}

O agronegócio configura-se de muita relevância nas últimas décadas para o crescimento econômico do Brasil, sendo que, nos momentos de recessão, como as dos anos de 2015, 2016 e 2020, ele evitou que a crise fosse mais intensa. Os dados do Ministério da Agricultura, Pecuária e Abastecimento (MAPA) evidenciam que, em 2019, a balança comercial do agronegócio expressou um superávit de US\$83,08 bilhões, sendo que ele foi responsável por $43 \%$ nas exportações totais do Brasil no mesmo ano (Brasil, 2020a).

Esse ótimo desempenho do agronegócio decorre, em parte, das políticas agrícolas implementadas em décadas passadas, as quais passaram de alto apoio do Governo a outras de maior participação do setor privado em sua implementação. As estimativas de suporte ao produtor (PSE), calculadas pela Organização para a Cooperação e Desenvolvimento Econômico 
(OCDE), apontam que a relação entre o total de subsídios e o volume de receitas do agricultor reduziu-se de 9,08\% em 2000 para 1,12\% em 2019, indicando que a agropecuária brasileira atualmente conta com um baixo grau de subvenção, quando comparada à concedida em outros países ${ }^{1}$.

Nos anos de 1970, houve grande implementação e considerável subsídio governamental nas políticas agrícolas, levando ao processo denominado de Modernização Conservadora da agropecuária. Segundo Mueller (2010) e Bacha (2018), nessa época, para modernizar a agropecuária, concedeu-se crédito rural farto e subsidiado, houve grande efetividade da política dos preços mínimos, pesquisa agropecuária (com a criação da Empresa Brasileira de Pesquisa Agropecuária, Embrapa) e extensão rural (uma vez instituída a Empresa Brasileira de Assistência Técnica e Extensão Rural, Embrater). Tal estratégia exigiu grandes gastos do Estado no apoio à agropecuária.

Não obstante o Governo Federal ter feito controle de preços, inclusive de produtos agropecuários e agroindustriais, para reduzir a inflação, em certos momentos dos anos de 1970, foram concedidos subsídios tributários para estimular as exportações de produtos agroindustriais, as quais também se favoreceram da política cambial adotada na época (Dias \& Amaral, 2001).

De acordo com Mueller (2010), a modernização do setor agropecuário, em especial do seu segmento exportador, estimulada por políticas públicas, estava de acordo com a visão de boa sociedade dos governos militares em vigor, que almejavam uma economia moderna, industrial e exportadora.

Após o segundo choque do petróleo, a inflação brasileira atingiu níveis ainda maiores nos anos de 1980. Nessa contextura, o objetivo central dos formuladores de política econômica era controlar a inflação e gerar divisas (moedas estrangeiras) necessárias para a importação de bens de capital (Hermann, 2011). Na agropecuária, o efeito disso foi uma queda na oferta de recursos do Estado para financiar a Política de Crédito Rural e a Política de Garantia de Preços Mínimos. A alta da taxa de juros e as más aplicações do crédito recebido anteriormente levaram à elevação da inadimplência dos agricultores, em especial, na segunda metade dos anos de 1980 (Bacha, 2018; Santiago \& Silva, 1999).

O começo dos anos de 1990 assistiu à discussão de um redirecionamento da política agrícola brasileira, com uma menor intervenção estatal ${ }^{2}$. Em razão de o então modelo operacional do crédito rural estar em desarmonia ante a necessidade de controle do déficit público, houve a necessidade de se encontrar modalidades distintas para estimular a adoção de fontes de recursos privados para financiar a agropecuária, como o uso da cédula de produto rural (CPR) em meados dos anos de 1990 e a busca de outra orientação de subvenção do Governo à agropecuária (Gasques \& Conceição, 2001).

Nessas circunstâncias, foi promulgada, em 1992, a Lei n 8.427, que regulamentou, entre outros, o mecanismo da subvenção econômica no crédito rural e nos preços mínimos. Essas subvenções, muitas vezes, ocorrem nas taxas de juros e nos preços.

A equalização de preços, por exemplo, consiste em subvenção equivalente à parcela do saldo devedor de financiamento que exceder o valor de mercado do produto financiado, em certas operações amparadas pela política de garantia de preços mínimos. De acordo com a

1 Para detalhes, consultar os dados disponibilizados em Organisation for Economic Co-operation and Development (2021).

${ }^{2}$ Gasques et al. (2010) declaram que as principais mudanças implementadas na política de cunho agrícola desde os anos de 1990 foram: redução dos subsídios, alteração no modo de atuação do Governo Federal no financiamento rural e instituição de instrumentos privados de comercialização. 
Lei n 8.427, a comercialização do produto agropecuário se dará no âmbito exclusivo do setor privado.

Por seu turno, a equalização da taxa de juros corresponde ao diferencial de taxas entre o custo de captação de recursos, acrescido dos custos administrativos e tributários a que estão sujeitas as instituições financeiras oficiais, e os encargos cobrados do tomador final do crédito (Brasil, 1992). O resultado final, após o advento desse mecanismo, foi a redução substancial do setor público no financiamento da agropecuária (Gasques et al., 2010; Gasques, 2017, 2021). Ressalta-se que essa modalidade de subvenção ao crédito rural é diferente da subvenção dada pelo Governo Federal no prêmio de seguro. No segundo caso, o Governo Federal atua arcando com de $20 \%$ a $40 \%$ do valor de contratação da apólice junto à seguradora, e o produtor assume o restante do valor do prêmio (Santos \& Freitas, 2017; Brasil, 2020b).

Com início em meados dos anos de 1990, registrou-se a instituição de vários programas de crédito rural, preços mínimos e seguro rural, que implicam maior participação do setor privado no apoio ao setor agropecuário e consequente menor subvenção do setor público a este segmento. Destacam-se, por exemplo, as criações, em 1994, da cédula de produto rural (CPR), na sua versão física e, em 2000, na sua variante financeira. Em 2004, foram criados instrumentos privados de financiamento do agronegócio - a letra de crédito do agronegócio (LCA), o certificado de recebível do agronegócio (CRA) e o certificado de direitos creditórios do agronegócio (CDCA) - gerando alavancagem na oferta de crédito pelo setor privado à agropecuária e sem direito de equalização da taxa de juros (Bacha, 2018; Schedenffeldt et al., 2021). Quanto à política de preços mínimos, se destacam a edição, em 1997, do Programa de Prêmio para Escoamento de Produto (PEP) e do contrato de opção de venda de produtos agropecuários (COVPA), aos quais se adicionaram, em 2004, o programa Contratos Privados de Opção de Venda e Prêmio de Risco de Opção Privada (PROP), e, ainda, em 2006, o programa Prêmio Equalizador Pago ao Produtor (PEPRO). Em 2004, foi instituído o Prêmio de Subvenção ao Seguro Rural (PSR). Esses programas, apesar de não serem exclusivos, foram fortemente direcionados à agropecuária não familiar e implicaram menor subvenção do setor público à agropecuária, como já ressaltado por Bacha (2018).

Simultaneamente, o Governo Federal criou programas de maior subvenção à agropecuária familiar: no crédito rural, foi gerado, em 1996, o PRONAF (Programa de Fortalecimento da Agricultura Familiar); para garantia de preços mínimos, foram constituídos o Programa de Aquisição de Alimentos (PAA), em 2003, e o Programa de Garantia de Preços da Agricultura Familiar (PGPAF), em 2006; e, no seguro rural, em 2004, sobrou estabelecido o Programa de Garantia da Atividade Agropecuária da Agricultura Familiar (Proagro-Mais).

Segundo Gasques et al. (2010) e Gasques (2017, 2021), no agregado, a importância das despesas do Governo Federal com a agropecuária foi reduzida, apesar de haver aumento da relevância das despesas com organização agrária (que atende, principalmente, à agricultura familiar) no total de gastos públicos feitos com a agropecuária. Em 1987, as despesas do Governo Federal com a agropecuária representaram $11,95 \%$ dos gastos públicos totais, e, em 2019, esta percentagem foi de $0,49 \%$. Nesses mesmos anos, as importâncias do componente organização agrária no total de gastos da União com a agropecuária foram de 4,3\% e 8,5\%, respectivamente.

Focando especificamente nas subvenções pagas pelo Governo Federal (que são parte de seus gastos com este setor) - e analisando os dados do $4^{\circ}$ Orçamento dos Subsídios da União, divulgados pela Secretaria de Avaliação, Planejamento, Energia e Loteria (SECAP) do Ministério da Economia (Brasil, 2020c) - observa-se que os gastos com a equalização de preços e taxa de juros à agropecuária (isto é, com crédito rural, preços mínimos e seguro rural) denotaram uma 
queda de aproximadamente $\mathrm{R} \$ 9,7$ bilhões em 2003 (67\% do total dos benefícios financeiros concedidos) para $\mathrm{R} \$ 5,6$ bilhões em 2019 ( $26 \%$ do total dos benefícios financeiros cedidos) - a preços de 2019, embora tenham atingido o ápice de $R \$ 20,8$ bilhões (22\% do total) em 2015.

Neste novo contexto de políticas agrícolas, em que a atuação de parte dos instrumentos de apoio do Governo à agropecuária vem por intermédio de equalização de preços e taxa de juros, surgem alguns questionamentos: a) Qual é a modalidade de subvenção econômica (tributária, financeira e creditícia) que implica maior apoio à agropecuária? b) Qual é a política de conteúdo agrícola que mais recebe benefícios totais destinados à agropecuária? c) Levando-se em consideração apenas os subsídios financeiros e creditícios, quanto é dado à agropecuária familiar (sob medição do PRONAF) e à agropecuária não familiar?

Considerando o exposto até aqui, o objetivo geral deste artigo é analisar a evolução e a composição dos gastos do Governo Federal com subvenções econômicas concedidas à agropecuária do País de 2003 a 2019. Com vistas a este propósito, recorre-se à análise de dados da Secretaria de Avaliação, Planejamento, Energia e Loteria (SECAP) do Ministério da Economia, a serem interpretados à luz da literatura existente.

\section{Revisão de Literatura}

Os autores de trabalhos que tratam da temática mais próxima ao objetivo deste artigo são: Cardoso (2011), Regazzini \& Bacha (2012), Santos \& Freitas (2017), Gasques et al. (2010), Gasques (2017), Betarelli Junior et al. (2019) e Xavier (2021).

Cardoso (2011) examinou os efeitos dos gastos com equalizações da taxa de juros no crescimento econômico e no bem-estar das grandes regiões brasileiras (Nordeste, Norte, Centro-Oeste, Sul e Sudeste), fazendo uso de um modelo de equilíbrio geral. A autora concluiu que, em geral, os gastos com equalizações da taxa de juros geram um baixo retorno em termos de crescimento econômico e bem-estar.

Regazzini \& Bacha (2012) estudaram a tributação e os gastos públicos na agropecuária brasileira. Os autores concluíram que o Governo Federal apresentou superávit fiscal em sua relação despesa-receita com este setor, uma vez que o total de tributos federais arrecadados sobre a agropecuária foi maior do que o valor total gasto com o setor, em termos reais, no período analisado (2000 a 2010).

Santos \& Freitas (2017) tiveram por finalidade discutir os gastos públicos com a agropecuária (subvenção ao crédito, preços mínimos, seguro e outros), utilizando-se de dados de 2000 a 2015 e disponibilizados no Sistema Integrado de Planejamento e Orçamento (SIOP) do Ministério do Planejamento. Observou-se que, do total de gastos com subvenções econômicas concedidas ao longo do citado período, a Política de Crédito Rural foi a mais favorecida, seguida pela Política de Preços Mínimos e pela Política de Seguro Rural.

Gasques et al. (2010) fazem uma análise histórica dos gastos do Governo Federal com a agropecuária desde o tempo do Império. Focando, mais especificamente, no período iniciado nos anos de 1980, os autores destacam a queda de importância desses gastos no total das despesas do Governo Federal e um viés em favor dos dispêndios com a chamada Organização Agrária, mediante o qual há maior apoio do Estado à parcela da agricultura familiar.

Utilizando-se de dados da Secretaria do Tesouro Nacional do Ministério da Economia, Gasques (2017) destaca que os gastos com equalizações da taxa de juros e de preços saltaram de $R \$ 5,63$ bilhões em 2010 para $R \$ 9,38$ bilhões em 2016, o que equivale a um crescimento nominal de $67 \%$. Neste último ano, em particular, o autor concluiu que o gasto com as 
equalizações da taxa de juros com a agricultura familiar e com a agricultura não familiar foi responsável por $97,5 \%$ das despesas com equalizações.

Betarelli Junior et al. (2019) examinaram os efeitos econômicos das equalizações da taxa de juros do crédito rural de investimento e de custeio em 2012, empregando uma matriz de insumo-produto. Os resultados estimados indicaram (diferentemente dos encontrados por Cardoso, 2011) que as despesas com equalizações da taxa de juros proporcionariam uma série de benefícios, destacando-se o fato de que o PIB se expandiria aproximadamente em $\mathrm{R} \$ 19,42$ bilhões, e haveria a criação de 568,2 mil empregos. Além disso, as projeções setoriais indicaram que os gastos com equalizações dos créditos de custeio e de investimento permitiriam o crescimento dos setores de produtos químicos, defensivos agrícolas, de máquinas e equipamentos, da agropecuária e comércio.

O trabalho de Xavier (2021) avalia os gastos públicos totais por grupos de função e de despesa e unidades orçamentárias, destacando aqueles com a agropecuária nos anos de 2000 a 2017. O autor conclui, entre outros pontos, que o setor agropecuário recebeu menos dos gastos feitos pelo Estado; não obstante, entre os gastos do Governo com este setor se evidencia que os desembolsos com subsídios à Política de Crédito Rural dirigida à agricultura familiar (PRONAF) e à Política de Seguro Rural exprimiram crescimento, ao passo que foram reduzidas as despesas com subvenções à Política de Garantia de Preços Mínimos.

Pode-se concluir, então, com a ideia de que os estudos retroexaminados avaliaram os gastos do governo com a agropecuária ou com equalizações com juros e preços, não especificamente os gastos com todas as subvenções econômicas (tributárias, financeiras ou creditícias) dadas à agropecuária. Além disso, mencionados estudos (com exceção do de Gasques (2017), e que apenas se refere ao PRONAF) dão pouca ênfase a identificar que grupo de produtores rurais (familiar versus não familiar) é privilegiado com a concessão de subvenções econômicas por parte do Governo Federal.

Neste artigo, procura-se, por via da análise de dados desagregados de benefícios fiscais, financeiros e creditícios, diagnosticar possíveis comportamentos diferenciadores da agropecuária em relação a outros segmentos da economia brasileira, e dentro da própria agropecuária, decompondo-a entre a familiar e a não familiar. Demanda-se, também, associar a evolução desses benefícios concedidos à agropecuária (tanto familiar quanto a não familiar) às mudanças ocorridas na política agrícola desde meados dos anos de 1990, quando houve a clara orientação do Governo Federal em criar novos mecanismos de crédito rural, preços mínimos e seguro agrícola apoiados pela iniciativa privada e que implicassem menor subsídio governamental à agricultura não familiar, ainda que procurando mantê-los para a agricultura não familiar. Isto se associa claramente com os grupos de interesses e o modo como eles se articulam na elaboração das políticas agrícolas (como destacado por Schwantes \& Bacha, 2019).

\section{Metodologia}

O presente artigo caracteriza-se como sendo uma pesquisa documental e explicativa, fazendo uso dos métodos observacional, estatístico e comparativo, consoante ensina Gil (2008). O artigo inicia-se como busca documental de carácter acadêmico (baseando-se nas informações do Ministério da Economia do Brasil referentes aos anos de 2003 a 2019), demandando-se, por via dos métodos observacional e estatístico, diagnosticar os comportamentos dos benefícios tributários, financeiros e creditícios concedidos à agropecuária versus os destinados aos demais setores da economia brasileira. Adotando este mesmo enfoque de pesquisa documental e esses dois mesmos métodos (observacional e estatístico), o texto prossegue para diagnosticar 
possíveis comportamentos distintos desses benefícios concedidos à agropecuária familiar em cotejo com a não familiar. Em seguida, tem-se uma pesquisa explicativa e usando o método comparativo para associar os resultados diagnosticados à mudança de orientação das políticas agrícolas, que ocorre desde meados dos anos de 1990, no intento de elaborar e implementar, em especial para a agricultura não familiar, novos programas de crédito rural, preços mínimos e seguro agrícola com maior apoio da iniciativa privada e menor subsídio governamental, em relação a manter programa similares e altamente subsidiados para a agropecuária familiar (como já destacado por Bacha, 2018, por exemplo).

Para analisar a tendência dos benefícios concedidos, e considerando as séries temporais das informações utilizadas, foram calculadas taxas geométricas de crescimento anual (TGCA). Essas taxas foram calculadas ajustando a regressão $\ln Y=a+b t$, em que $Y$ é o valor da subvenção e t é o tempo. A TGCA é o antilog do coeficiente b subtraído de hum. Essas taxas aparecem ao final das tabelas a serem apresentadas.

Os dados aqui utilizados foram retirados do relatório "4 Orçamento dos Subsídios da União", divulgado pela Secretaria de Avaliação, Planejamento, Energia e Loteria (SECAP) do Ministério da Economia (Brasil, 2020c). Essas informações dizem respeito aos subsídios ou benefícios tributários (em linhas gerais, são impactos na política fiscal decorrentes de, por exemplo, anistia, remissões e modificação de alíquotas tributárias), financeiros (total de gastos públicos efetivos com equalização de taxa de juros e de preços) e creditícios (recursos destinados a fundos ou programas). Salienta-se que os dados foram deflacionados pelo IGP-DI (base $2019=100$ ).

É importante destacar que subsídios são parte dos gastos do Governo (registrados em "Outras Despesas Correntes"). Os gastos do Governo ocorrem nas formas de grupo de função e grupo de despesa. No grupo de função, os gastos são classificados em: Legislativo; Judiciário; Essencial à Justiça; Administração; Defesa Nacional; Segurança Pública; Relações Exteriores; Assistência Social; Previdência Social; Saúde; Trabalho; Educação; Cultura; Direitos da Cidadania; Urbanismo; Habitação; Saneamento; Gestão Ambiental; Ciência e Tecnologia; Agricultura; Organização Agrária; Indústria; Comércio e Serviços; Comunicações; Energia; Transporte; Desporto e Lazer; e Encargos Especiais. O grupo de despesa engloba os gastos com: Pessoal e Encargos Sociais; Juros e Encargos da Dívida; Investimentos; Inversões Financeiras; Amortização da Dívida, além de Outras Despesas Correntes (nas quais estão as subvenções econômicas). Para obtenção de detalhes, sugere-se consultar Xavier (2021).

Ademais, tornou-se necessário criar grupos de categorias para cada uma das classes de subsídios. Assim, restaram separados os subsídios concedidos unicamente à agropecuária dos alocados conjuntamente à agropecuária e à agroindústria e daqueles destinados a outros setores.

Quanto à subvenção tributária concedida unicamente à agropecuária, os recursos dizem respeito a Isenções a Imóveis Rurais (isenção do pagamento do Imposto sobre a Propriedade Territorial Rural, ITR) e aqueles relacionados ao Seguro Rural. Os benefícios tributários concedidos conjuntamente à agropecuária e à agroindústria estão relacionados a Álcool, Biodiesel e à Agricultura e Agroindústria - Desoneração da Cesta Básica.

Os benefícios financeiros concedidos unicamente à agropecuária se referem ao montante despendido com equalizações referentes: a) Política de Crédito Rural (PRONAF, Custeio Agropecuário, Programa Especial de Saneamento de Ativos, Empréstimos do Governo Federal, FUNCAFÉ, Securitização Agrícola, Programa de Revitalização de Cooperativas de Produção Agropecuária, Programa de Recuperação da Lavoura Cacaueira e Subvenção nas Operações de Crédito Rural nas áreas da SUDENE/SUDAM); b) Política de Garantia de Preços Mínimos (Aquisições do Governo Federal e Estoques Estratégicos, Garantia e Sustentação de Preços da 
Agricultura Familiar e Subvenção aos Produtores da Borracha Natural); e, à Política de Seguro Rural (Subvenção Econômica ao Prêmio de Seguro Rural).

Já os subsídios financeiros concedidos conjuntamente à agropecuária e à agroindústria dizem respeito às Operações de Investimento Rural e Agroindustrial, ao Programa de Apoio ao Setor Sucroalcooleiro, aos Investimentos na Região Centro-Oeste (equalização via FAT) e Programa de Garantia e Sustentação de Preços.

Por último, os benefícios creditícios no que tange apenas à agropecuária estão relacionados ao FUNCAFÉ (financiamento), ao Fundo de Terras e da Reforma Agrária - Banco da Terra, ao Programa Especial de Saneamento de Ativos, ao PRONAF (financiamento), ao Programa de Recuperação da Lavoura Cacaueira (financiamento), ao Programa de Revitalização de Cooperativas de Produção Agropecuária (financiamento) e à Securitização Agrícola. Salienta-se que, diferentemente das categorias de subsídios anteriores, não houve benefícios creditícios concedidos conjuntamente à agropecuária e à agroindústria.

\section{Resultados e Discussão}

A Tabela 1 contém os valores (a preços de 2019) de todas as categorias de subvenções econômicas concedidas pelo Governo Federal a todos os setores da economia brasileira nos anos de 2003 e 2019. Constata-se que o total de subsídios dados pelo Governo Federal aumentou, em valores reais, de 2003 a 2015 (durante as gestões petistas, de orientação política de esquerda), e decresceu de 2016 a 2019 (com governos de orientação neoliberal e, portanto, mais preocupados com o controle de gastos públicos). Vê-se nesses dados que a alteração dos grupos que compõem a administração central implica alteração dos beneficiários com gastos públicos, como já alertado por Mueller (1983), Lamounier (1994) e Schwantes \& Bacha (2019). De acordo com Mueller (1983) e Sabourin (2007), no Brasil, o modelo de governo predominante é o pluralista, o qual se baseia em negociações entre grupos de interesse. No contexto agrícola, há grupos que defendem os interesses dos agricultores mais capitalizados (que transitam, normalmente, em torno do Ministério da Agricultura, Pecuária e Abastecimento, e existem outros que advogam em favor da agricultura familiar (e que transitavam, até 2016, ao redor do então Ministério do Desenvolvimento Agrário e que desde então estão concentrados, em parte, na Secretaria Especial de Desenvolvimento Agrário e Agricultura Familiar). Esses aspectos são explorados ao se avaliar a distribuição de benefícios entre a agricultura familiar e não familiar.

Nota-se que, de 2003 a 2017, a modalidade de subsídios que mais cresceu e expressou o maior percentual de participação no montante total concedido de subvenções foi a tributária, seguida da creditícia. Nos anos de 2018 e 2019, as subvenções tributárias continuaram a ser as majoritárias, mas as subvenções financeiras ultrapassaram as creditícias.

Observa-se que, em valores reais, os benefícios financeiros concedidos a todos os setores da economia (ou seja, o montante despendido pelo Governo Federal com equalizações de preços e da taxa de juros) oscilou, recorrentemente, dos anos de 2003 e 2014, expandindo-se abruptamente em 2015, e voltando a decrescer em 2016. Em termos relativos, o dispêndio máximo com essa modalidade aconteceu em 2004 , quando atingiu $20,86 \%$ do somatório de todos os benefícios concedidos.

A Figura 1 mostra que o valor deflacionado das subvenções federais (tributária, financeira e creditícia) concedidas à agropecuária em 2003 foram de $R \$ 11.803 .428 .967,33$ e em 2019 de $R \$$ 6.266.345.000,00 (todos a preços de 2019). Passou-se de $9 \%$ do total dado dessas subvenções na economia brasileira em 2003 para 1,8\% em 2019. Considerando a participação das subvenções dada à agropecuária sobre o PIB deste setor, tem-se que esta foi de 4,4\% em 2003 e de 1,9\% 


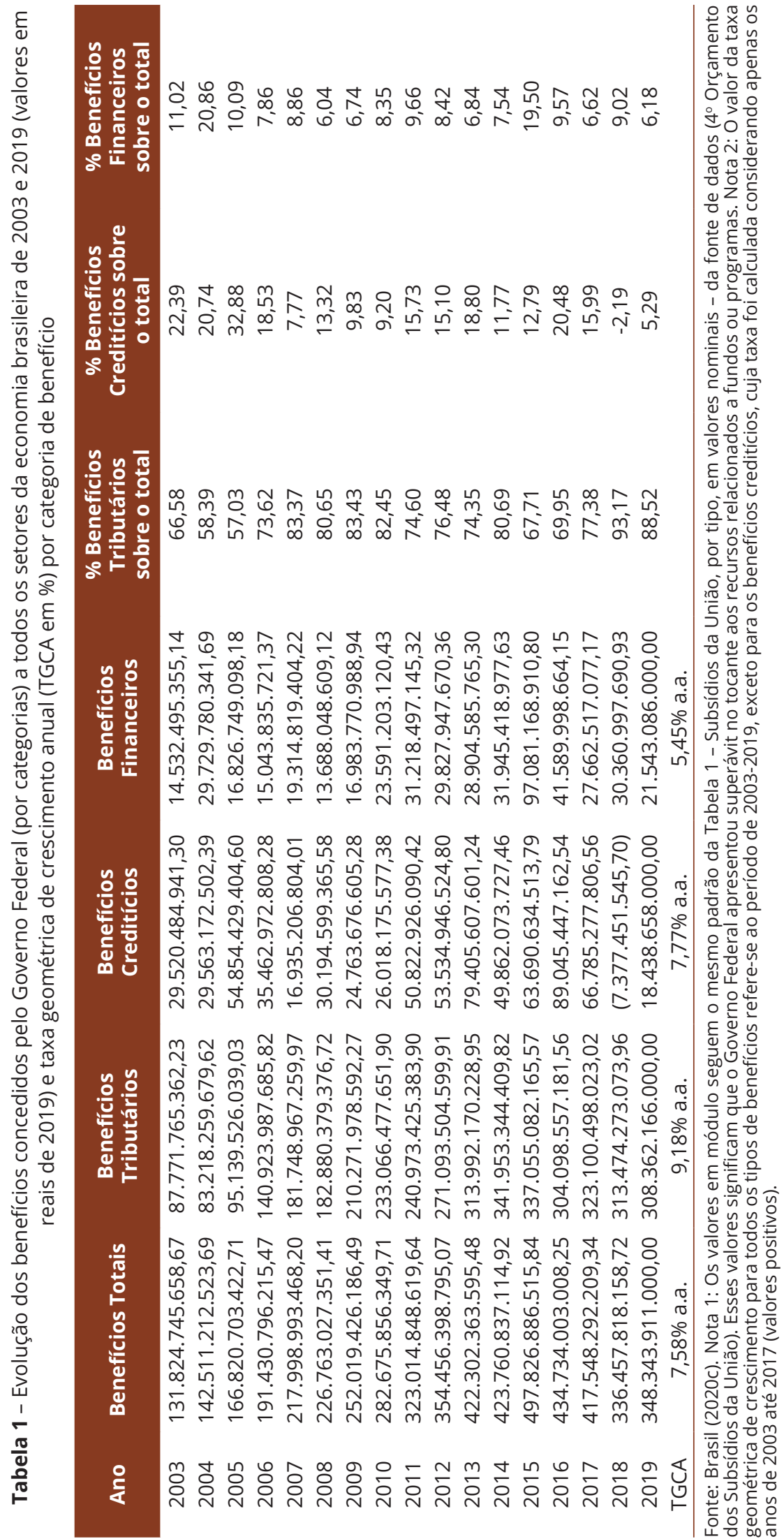


em 2019. Deve-se destacar o fato de que, no ano de 2015, ocorreu intensiva elevação de subvenções à agropecuária, em especial via crédito rural, as quais não estavam previstas no orçamento aprovado em 2014 e que constituiu um dos motivos para o impeachment da então Presidente Dilma Rousseff. Tais subvenções, entretanto, voltaram a diminuir, relativamente, a partir de 2016.

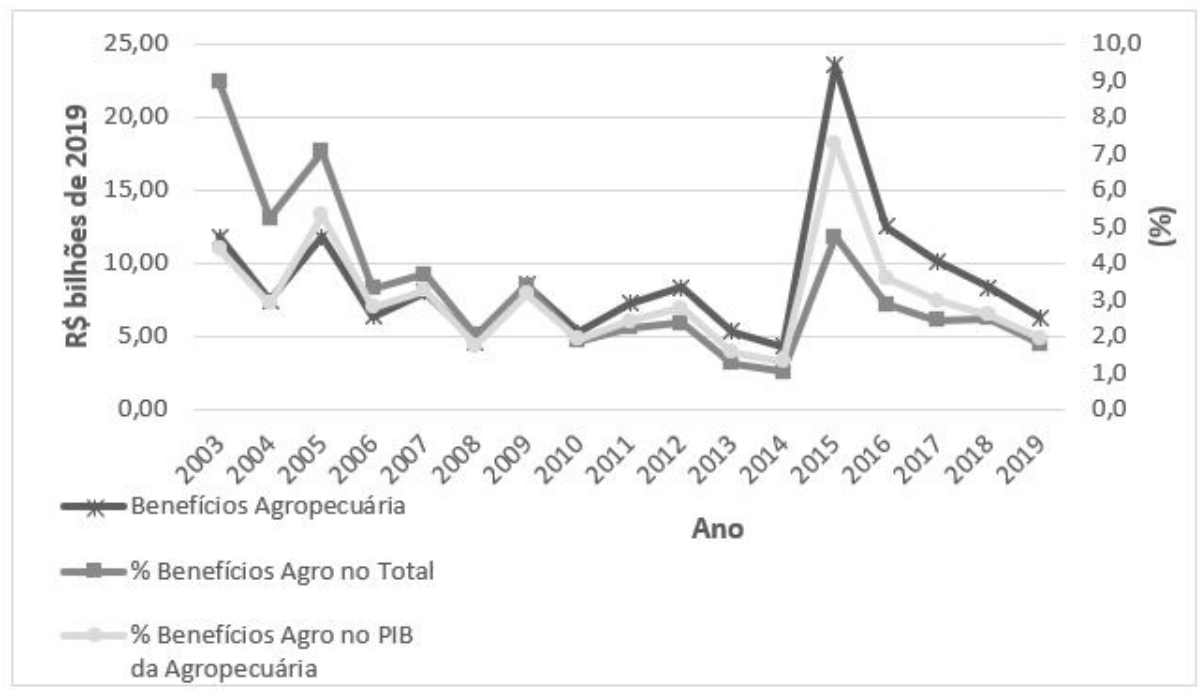

Figura 1 - Evolução dos benefícios cedidos à agropecuária (2003-2019) Fonte: Brasil (2020c). Nota: PIB da agropecuária deflacionado pelo IGP-DI (base $2019=100$ ).

A modalidade de subvenção econômica que mais transfere recursos à agropecuária é a financeira (diferente do que ocorre para toda a economia, cuja modalidade principal de subsídio é a tributária). Observa-se que, pela Figura 2, houve um aumento abrupto no montante dessas subvenções em 2015, que foi de $\mathrm{R} \$ 20.883 .293 .781$,32 (88,81\% do total dado ao setor). Em 2019, os benefícios financeiros cedidos ao setor totalizaram $R \$ 5.623 .284 .000,00$, ou seja, $89,74 \%$ do total das subvenções federais destinadas à agropecuária.

No tocante à participação dos instrumentos de política agrícola (crédito rural, preços mínimos e seguro rural) nos benefícios direcionados à agropecuária, constata-se que, em 2019, 83,7\% do total de subvenções federais dadas à agropecuária ( $R \$ 6.266 .345 .000,00)$ foram vinculadas à Política de Crédito Rural, 3,7\% foram vinculadas à Política de Garantia de Preços Mínimos e $11,9 \%$ à Política de Seguro Rural (ver dados da Tabela 2) 3 . Em termos de taxa de crescimento, os dados da Tabela 2 apontam que os subsídios concedidos ao seguro rural e ao crédito rural expuseram progressos (de 52,22\% a.a. e de 0,52\% a.a., respectivamente). Sobre o crédito rural, em particular, esse baixo crescimento é passível de estar relacionado à criação dos novos instrumentos de financiamento privado do agronegócio (expostos em Bacha, 2018) que diminuíram a necessidade de subvenções do governo ao mencionado segmento.

\footnotetext{
${ }^{3}$ Este resultado não é similar ao encontrado por Santos \& Freitas (2017), segundo os quais, o montante de gastos com subvenções com a Política de Seguro Rural representou apenas 1,6\% do total de gastos com a agricultura de 2000 a 2015, ao passo que os desembolsos com subvenções com a Política de Preços Mínimos representaram 22,5\% em relação ao total de gastos com a agricultura. Isto mostra que o Governo Federal, tem, relativamente, priorizado o seguro rural em suas subvenções na segunda metade da segunda década do século XXI.
} 


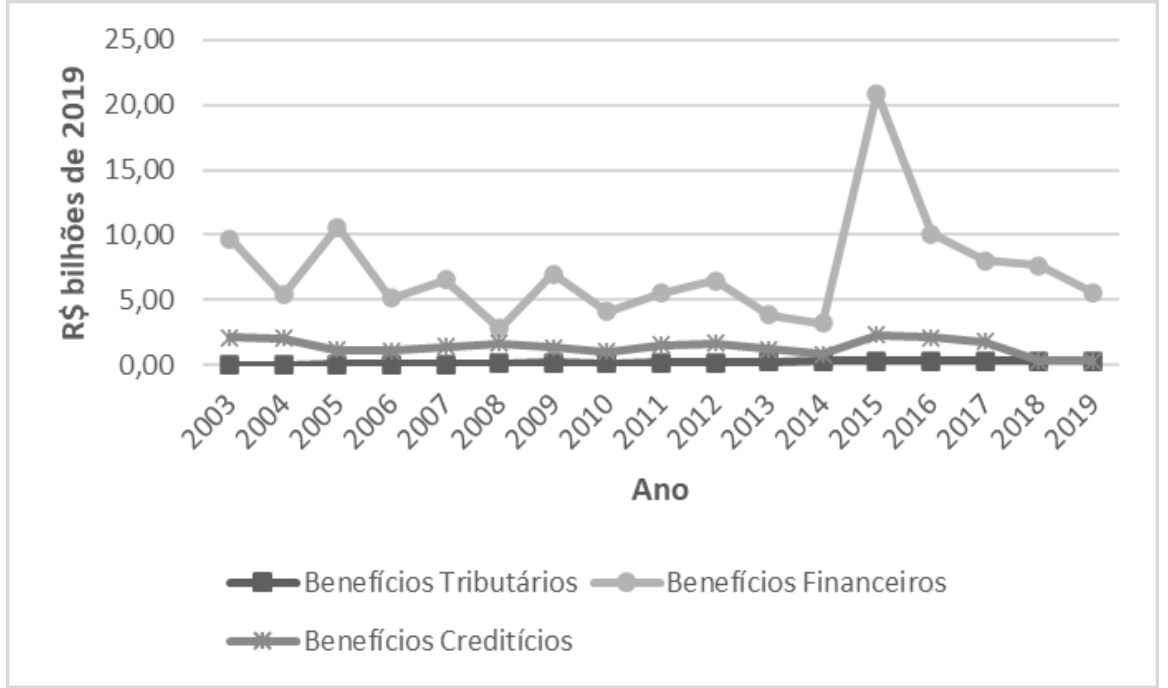

Figura 2 - Evolução das categorias de subvenções econômicas no total distribuído à agropecuária (2003-2019) Fonte: Brasil (2020c).

Tabela 2 - Participação dos benefícios dados (tributários, financeiros e creditícios) ao crédito rural, aos preços mínimos e ao seguro rural (2003-2019) e taxa geométrica de crescimento anual (em \%)

\begin{tabular}{|c|c|c|c|c|c|c|c|}
\hline Ano & $\begin{array}{l}\text { Benefícios } \\
\text { Agropecuária } \\
\text { (R\$ de 2019) }\end{array}$ & $\begin{array}{l}\text { Crédito Rural } \\
\text { (R\$ de 2019) }\end{array}$ & $\begin{array}{c}\text { Preços } \\
\text { Mínimos (R\$ } \\
\text { de 2019) }\end{array}$ & $\begin{array}{l}\text { Seguro Rural } \\
\text { (R\$ de 2019) }\end{array}$ & $\begin{array}{c}\% \\
\text { Crédito } \\
\text { Rural }\end{array}$ & $\begin{array}{l}\text { \% Preços } \\
\text { Mínimos }\end{array}$ & $\begin{array}{c}\% \\
\text { Seguro } \\
\text { Rural }\end{array}$ \\
\hline 2003 & $11.803 .428 .967,33$ & $9.870 .827 .385,27$ & $1.932 .601 .582,06$ & 0,00 & 83,6 & 16,4 & 0,0 \\
\hline 2004 & $7.469 .223 .026,21$ & $6.963 .758 .215,97$ & $505.450 .873,30$ & $13.936,94$ & 93,2 & 6,8 & 0,0 \\
\hline 2005 & $11.773 .877 .274,20$ & $9.850 .891 .273,47$ & $1.874 .828 .115,60$ & $5.074 .609,33$ & 83,7 & 15,9 & 0,0 \\
\hline 2006 & $6.342 .512 .118,96$ & $5.687 .007 .552,71$ & $538.662 .512,33$ & $67.064 .261,78$ & 89,7 & 8,5 & 1,1 \\
\hline 2007 & $8.035 .151 .774,36$ & $8.113 .254 .756,54$ & $(254.986 .914,34)$ & $125.013 .167,38$ & 101,0 & $-3,2$ & 1,6 \\
\hline 2008 & $4.605 .161 .955,80$ & $4.462 .245 .273,99$ & $(289.628 .356,23)$ & $387.570 .648,53$ & 96,9 & $-6,3$ & 8,4 \\
\hline 2009 & $8.528 .626 .539,89$ & $3.671 .147 .404,77$ & $4.367 .415 .400,16$ & $443.720 .784,99$ & 43,0 & 51,2 & 5,2 \\
\hline 2010 & $5.281 .188 .345,93$ & $2.871 .760 .289,73$ & $1.913 .819 .524,95$ & $449.501 .955,97$ & 54,4 & 36,2 & 8,5 \\
\hline 2011 & $7.255 .076 .971,57$ & $7.385 .921 .809,87$ & $(697.004 .837,79)$ & $520.854 .468,47$ & 101,8 & $-9,6$ & 7,2 \\
\hline 2012 & $8.339 .429 .574,19$ & 7.782.104.642,93 & $(98.840 .687,33)$ & $611.105 .716,15$ & 93,3 & $-1,2$ & 7,3 \\
\hline 2013 & $5.308 .343 .642,13$ & $4.430 .681 .549,16$ & $52.349 .729,33$ & $780.200 .559,84$ & 83,5 & 1,0 & 14,7 \\
\hline 2014 & $4.335 .248 .564,79$ & $2.890 .200 .237,38$ & $609.355 .939,03$ & $790.166 .086,29$ & 66,7 & 14,1 & 18,2 \\
\hline 2015 & $23.514 .555 .573,21$ & $22.324 .564 .670,41$ & $202.159 .225,31$ & $941.398 .647,23$ & 94,9 & 0,9 & 4,0 \\
\hline 2016 & $12.503 .366 .233,78$ & $11.193 .526 .404,11$ & $129.455 .566,74$ & $1.134 .562 .882,06$ & 89,5 & 1,0 & 9,1 \\
\hline 2017 & $10.157 .769 .594,75$ & $9.128 .043 .056,06$ & $127.422 .947,68$ & $855.355 .155,70$ & 89,9 & 1,3 & 8,4 \\
\hline 2018 & $8.345 .211 .741,26$ & 7.110.044.109,29 & $510.574 .711,09$ & $678.598 .332,79$ & 85,2 & 6,1 & 8,1 \\
\hline 2019 & $6.266 .345 .000,00$ & $5.245 .485 .000,00$ & $230.818 .000,00$ & $745.051 .000,00$ & 83,7 & 3,7 & 11,9 \\
\hline TGCA & 0,45\% a.a. & 0,52\% a.a. & & $52,22 \%$ a.a. & & & \\
\hline
\end{tabular}

Fonte: Brasil (2020c). Nota 1: Os valores em módulo seguem o mesmo padrão da Tabela 1 - Subsídios da União, por tipo, em valores nominais - da fonte de dados (4 Orçamento dos Subsídios da União). Nota 2: O valor da taxa geométrica de crescimento de benefícios cedidos à agropecuária e do crédito rural refere-se ao período de 2003-2019, exceto para o seguro rural, cuja taxa foi computada considerando apenas os anos de 2004 até 2019 (valores positivos). Em razão da existência de valores negativos para os benefícios dados aos preços mínimos, a TGC anual não foi calculada para eles

O crédito rural é responsável por aumentar a demanda por insumos e, consequentemente, permitindo a expansão da produção da agropecuária, inclusive de parte da agropecuária familiar (Costa, 2018; Teixeira et al., 2014). A preocupação do Governo Federal, desde os anos de 1990, é propor mais instrumentos privados de financiamento do agronegócio, diminuindo seus gastos nesta modalidade de política agrícola (ver Bacha, 2018). Os dados mostram que 
as subvenções ao crédito rural diminuíram de 2008 a 2010, o que é capaz de estar relacionado à crise financeira internacional dos anos de 2008 e 2009.

A baixa participação do seguro rural nos subsídios direcionados à agropecuária nos anos de 2003 a 2007 decorre do fato de que este instrumento ainda estava em redefinição, em virtude, dentre outras razões, da baixa participação efetiva do Governo em sua concessão, da legislação ultrapassada, das falhas de mercado (risco moral e seleção adversa) e ineficácia do Fundo de Estabilidade do Seguro Rural (FESR) para socorrer as seguradoras após a ocorrência de um evento de natureza catastrófica (Ozaki, 2006, 2007). O Programa Prêmio de Subvenção ao Seguro Rural (PSR), que hoje é o maior de seguro rural, conduzido em parceria pelo Governo Federal e a iniciativa privada, foi criado no final de 2004 e teve maior cobertura a partir do final da primeira década do século XXI, apesar de terem ocorrido contingenciamentos de recursos em 2009 e 2010, conforme declararam Macedo et al. (2013).

Por sua vez, a subvenção concedida à Política de Preços Mínimos (por via da equalização de preços) tem representado um percentual baixo do total das subvenções dadas à agropecuária na segunda década do século XXI, como já tinha sido revelado por Gasques (2017)4.

Analisando apenas os subsídios financeiros e creditícios transferidos pelo Governo Federal à agropecuária, que, em 2019, totalizaram R \$ 5.916.565.000,00, constata-se que a agropecuária familiar (via PRONAF) representou 47,09\% deste subtotal, ao passo que a agropecuária não familiar (por intermédio de programas outros que não o PRONAF) respondeu por $45,47 \%$ deste subtotal; os 7,44\% restantes $(R \$ 440.262 .000,00)$ desse montante correspondem à parcela direcionada à Política de Seguro Rural. Salienta-se também que o crédito direcionado à agropecuária familiar teve uma trajetória de expansão de 5,96\% a.a. de 2003 a 2019, diferentemente do financiamento dado à agropecuária não familiar, o qual teve um ritmo de regressão de 2,61\% a.a. (Tabela 3). Os benefícios financeiros e creditícios à agropecuária mostraram um crescimento de apenas $0,16 \%$ a.a. no período. Conclui-se, portanto, que há um favorecimento da agricultura familiar na concessão de benefícios financeiros e creditícios.

O acima exposto está coerente com a exposição sobre as mudanças realizadas, desde meados de 1990 (e comentadas na Introdução do artigo), de se criar novos programas de crédito rural operados, em grande parte, pela iniciativa privada, tais como a instituição da cédula de produto rural (CPR) e os novos instrumentos privados de financiamento do agronegócio, como a letra de crédito do agronegócio (LCA), o certificado de recebíveis do agronegócio (CRA) e os certificados de direitos creditórios do agronegócio (CDCA). Esses instrumentos implicam menor apoio do Governo e são fortemente usados pela agropecuária não familiar (como exposto em Bacha (2018), Schedenffeldt et al. (2021), por exemplo).

De outro lado, reconhecendo a importância da agricultura familiar na oferta interna de alimentos e sua possível maior vulnerabilidade, outros programas foram a ela juntados, como o PRONAF. Para operacioná-lo, o Governo Federal precisa conceder subvenções econômicas às instituições financeiras para que elas ofereçam crédito a taxas de juros diferenciadas e menores aos pequenos agricultores. Os dados do Banco Central do Brasil (2020) mostram que o volume de crédito direcionado a esse segmento de produtores, o crédito do PRONAF, saltou de $R \$ 8$ bilhões em 2003 (9,94\% do total) para $R \$ 25,7$ bilhões em 2019 (14,4\% do total) ${ }^{5}$, taxa de crescimento real de $221 \%$.

De outra parte, observa-se que os subsídios financeiros concedidos à Política de Preços Mínimos (via sistema de equalização de preços) têm privilegiado, repetidamente, o segmento da

${ }^{4}$ Gasques (2017) mostra que o gasto com a equalização de preços para a agricultura familiar e não familiar como um todo representou apenas 2,5\% do total de gastos com equalização na agropecuária no ano de 2016.

5 Dados deflacionados pelo IGP-DI - base $2019(=100)$. 
agropecuária não familiar em detrimento da agropecuária familiar no decurso dos últimos anos. Em 2019, a equalização de preços para a agropecuária não familiar foi de $R \$ 210.042 .000,00$, enquanto a equalização de preços para a agropecuária familiar foi de $R \$ 20.776 .000,00$, ou seja, o montante destinado à primeira parcela de agricultores foi mais de dez vezes ao que foi dado ao último grupo de produtores.

Tabela 3 - Montante de benefícios financeiros e creditícios concedidos pelo Governo Federal à agropecuária de2003 e 2019 (valores em reais de 2019) e taxa geométrica de crescimento anual, TGCA (em \%)

\begin{tabular}{ccccccc} 
Ano & $\begin{array}{c}\text { Benefícios } \\
\text { Agropecuária }\end{array}$ & Pronaf & Não Pronaf & $\begin{array}{c}\text { Preço Mínimo } \\
\text { Agropecuária } \\
\text { Familiar }\end{array}$ & $\begin{array}{c}\text { Preço Mínimo } \\
\text { Agropecuária } \\
\text { Não Familiar }\end{array}$ & Seguro Rural \\
\hline 2003 & $11.803 .428 .967,33$ & $2.486 .331 .140,14$ & $7.384 .496 .245,12$ & 0,00 & $1.932 .601 .582,06$ & 0,00 \\
2004 & $7.469 .223 .026,21$ & $2.606 .790 .139,83$ & $4.356 .968 .076,14$ & 0,00 & $505.450 .873,30$ & $13.936,94$ \\
2005 & $11.730 .793 .998,40$ & $1.784 .532 .950,45$ & $8.066 .358 .323,02$ & 0,00 & $1.874 .828 .115,60$ & $5.074 .609,33$ \\
2006 & $6.292 .734 .326,82$ & $2.657 .545 .817,34$ & $3.029 .461 .735,37$ & 0,00 & $538.662 .512,33$ & $67.064 .261,78$ \\
2007 & $7.983 .281 .009,58$ & $1.846 .619 .650,84$ & $6.266 .635 .105,70$ & 0,00 & $(254.986 .914,34)$ & $125.013 .167,38$ \\
2008 & $4.463 .067 .521,41$ & $1.967 .455 .608,29$ & $2.494 .789 .665,70$ & 0,00 & $(289.628 .356,23)$ & $290.450 .603,64$ \\
2009 & $8.361 .867 .444,26$ & $1.638 .427 .514,29$ & $2.032 .719 .890,49$ & 0,00 & $4.367 .415 .400,16$ & $323.304 .639,33$ \\
2010 & $5.125 .721 .303,64$ & $95.534 .202,93$ & $2.776 .226 .086,80$ & 0,00 & $1.913 .819 .524,95$ & $340.141 .488,96$ \\
2011 & $7.089 .565 .763,14$ & $3.655 .588 .580,01$ & $3.730 .333 .229,86$ & 0,00 & $(697.004 .837,79)$ & $400.648 .791,07$ \\
2012 & $8.157 .842 .448,11$ & $3.990 .845 .335,89$ & $3.791 .259 .307,05$ & 0,00 & $(98.840 .687,33)$ & $474.578 .492,51$ \\
2013 & $5.061 .316 .442,15$ & $2.704 .764 .305,11$ & $1.725 .917 .244,05$ & 0,00 & $52.349 .729,33$ & $578.285 .163,66$ \\
2014 & $4.047 .490 .217,58$ & $939.170 .641,38$ & $1.951 .029 .596,00$ & $3.588 .560,20$ & $605.767 .378,83$ & $547.934 .041,17$ \\
2015 & $23.225 .540 .638,21$ & $13.048 .672 .963,89$ & $9.275 .891 .706,52$ & $6.113 .326,33$ & $196.045 .898,98$ & $698.816 .742,48$ \\
2016 & $12.209 .541 .764,42$ & $6.545 .958 .273,36$ & $4.647 .568 .130,75$ & $6.565 .338,85$ & $122.890 .227,89$ & $886.559 .793,57$ \\
2017 & $9.838 .857 .867,36$ & $4.928 .658 .523,76$ & $4.199 .384 .532,31$ & $5.464 .750,61$ & $121.958 .197,07$ & $583.391 .863,62$ \\
2018 & $8.021 .355 .630,04$ & $3.391 .919 .531,49$ & $3.718 .124 .577,80$ & $10.132 .765,13$ & $500.441 .945,96$ & $400.736 .809,66$ \\
2019 & $5.916 .565 .000,00$ & $2.765 .470 .000,00$ & $2.480 .015 .000,00$ & $20.776 .000,00$ & $210.042 .000,00$ & $440.262 .000,00$ \\
TGCA & $0.16 \%$ a.a. & $5,96 \%$ a.a. & $-2,61 \%$ a.a. & & & $47,47 \%$ a.a. \\
\hline
\end{tabular}

Fonte: Brasil (2020c). Nota: O valor da taxa geométrica de crescimento de benefícios cedidos à agropecuária e do crédito rural (PRONAF e Não PRONAF) refere-se ao período de 2003-2019, exceto para o seguro rural, cuja taxa foi computada considerando apenas os anos de 2004 até 2019 (valores positivos). Pela presença de valores negativos para os benefícios dados aos preços mínimos para a agropecuária não familiar, a TGC anual não foi calculada para eles. E em razão dos poucos dados anuais existentes para as subvenções dadas aos preços mínimos para a agropecuária familiar, a TGC anual não foi calculada para os mesmos

Esse resultado já era esperado, uma vez que, como destacaram Schwantes \& Bacha (2019), a Política de Garantia de Preços Mínimos tem privilegiado, historicamente, o milho e o arroz ${ }^{6}$, cujas principais regiões produtoras são o Centro-Oeste e o Sul do Brasil, respectivamente (Instituto Brasileiro de Geografia e Estatística, 2019), que exprimem o primeiro e o terceiro lugares do valor bruto da produção (VBP) dos estabelecimentos agropecuários não familiares no Brasil, de acordo com o Censo Agropecuário de 2017.

Além disso, a Tabela 3 indica que a Subvenção Econômica ao Prêmio de Seguro Rural (PSR) mostrou uma trajetória de expansão até 2016, quando o montante subvencionado totalizou $\mathrm{R} \$ 886.559 .793,57$ (a preços de 2019), decrescendo logo em seguida, para atingir metade deste valor em 2019. Nota-se que a taxa geométrica de crescimento anual da Subvenção Econômica ao Prêmio de Seguro Rural de 2004 até 2019 foi de 47,47\%, fato significativo de que o Governo Federal, cada vez mais, almeja melhorar a gestão de riscos no campo, por intermédio da ampliação do número de apólices contratadas.

${ }^{6}$ Schwantes \& Bacha (2019) realçam que, não obstante o segmento de grãos tenha sido o mais favorecido pela Política de Garantia de Preços Mínimos até os anos de 1990, a partir dos anos 2000, essa política passou por um novo direcionamento, englobando mais produtos (por exemplo, cera de carnaúba, a juta e a malva, a mamona, o casulo de seda, a castanha-do-pará, o guaraná, o milho-pipoca e o leite) e operando em outras regiões do Brasil. 
As informações sobre benefícios tributários (ver Tabela 4) nos permite apenas identificar, em separado, para a agropecuária os dados referentes ao seguro rural e ao ITR. A coluna Parcialmente Rural traz os benefícios tributários em conjunto para agropecuária e agroindústria. Em 2019, o seguro rural foi agraciado com $\mathrm{R} \$$ 304.789.000,00 de subvenções tributárias, o que equivaleu a $0,10 \%$ do total da subvenção tributária dada a todos os setores da economia brasileira, enquanto as isenções aos imóveis rurais (ITR) somaram R $\$ 44.991 .000$ (0,01\% do total). Por seu turno, a agropecuária em conjunto com a agroindústria (coluna "parcialmente rural" da Tabela 4) foi favorecida com $\mathrm{R} \$ 32.328 .465 .000,00$ nesse ano, o que representou $10,48 \%$ do total dos incentivos fiscais cedidos. Adicionalmente, os dados da Tabela 4 indicam que os benefícios tributários cedidos à agropecuária em conjunto com a agroindústria cresceram de 2003 a 2019, bem como aqueles destinados aos outros setores. As subvenções tributárias cedidas ao seguro rural também se elevaram de 2008 a 2019. Por outro lado, as isenções a imóveis rurais (ITR) apresentaram um padrão de decrescimento de 2005 a 2019 (diminuição de $0,22 \%$ a.a.).

Tabela 4 - Benefícios Tributários cedidos (em R\$ de 2019) e taxa geométrica de crescimento anual, TGCA (em \%)

\begin{tabular}{cccccccc} 
Ano & $\begin{array}{c}\text { Isenções a } \\
\text { Imóveis Rurais } \\
\text { (ITR) }\end{array}$ & Parcialmente Rural & Seguro Rural & Demais & $\begin{array}{c}\text { (\%) Isenções } \\
\text { Móveis } \begin{array}{c}\text { Seguro Total de Benefícios } \\
\text { Rural }\end{array} \\
\text { Tributários }\end{array}$ \\
\hline 2003 & 0,00 & $4.517 .343 .415,91$ & 0,00 & $83.254 .421 .946,31$ & 0,00 & 0,00 & $87.771 .765 .362,23$ \\
2004 & 0,00 & $4.321 .796 .580,96$ & 0,00 & $78.896 .463 .098,65$ & 0,00 & 0,00 & $83.218 .259 .679,62$ \\
2005 & $43.083 .275,81$ & $3.568 .031 .059,18$ & 0,00 & $91.528 .411 .704,04$ & 0,05 & 0,00 & $95.139 .526 .039,03$ \\
2006 & $49.777 .792,14$ & $9.625 .010 .406,66$ & 0,00 & $131.249 .199 .487,03$ & 0,04 & 0,00 & $140.923 .987 .685,82$ \\
2007 & $51.870 .764,78$ & $13.491 .701 .816,50$ & 0,00 & $168.205 .394 .678,69$ & 0,03 & 0,00 & $181.748 .967 .259,97$ \\
2008 & $44.974 .389,51$ & $13.543 .603 .428,36$ & $97.120 .044,88$ & $169.194 .681 .513,97$ & 0,02 & 0,05 & $182.880 .379 .376,72$ \\
2009 & $46.342 .949,97$ & $17.751 .885 .086,71$ & $120.416 .145,66$ & $192.353 .334 .409,93$ & 0,02 & 0,06 & $210.271 .978 .592,27$ \\
2010 & $46.106 .575,27$ & $16.993 .341 .690,25$ & $109.360 .467,02$ & $215.917 .668 .919,36$ & 0,02 & 0,05 & $233.066 .477 .651,90$ \\
2011 & $45.305 .531,02$ & $18.218 .018 .019,55$ & $120.205 .677,40$ & $222.589 .896 .155,93$ & 0,02 & 0,05 & $240.973 .425 .383,90$ \\
2012 & $45.059 .902,43$ & $19.839 .005 .716,54$ & $136.527 .223,64$ & $251.072 .911 .757,30$ & 0,02 & 0,05 & $271.093 .504 .599,91$ \\
2013 & $45.111 .803,81$ & $27.127 .159 .059,91$ & $201.915 .396,17$ & $286.617 .983 .969,05$ & 0,01 & 0,06 & $313.992 .170 .228,95$ \\
2014 & $45.526 .302,09$ & $28.072 .862 .993,19$ & $242.232 .045,12$ & $313.592 .723 .069,43$ & 0,01 & 0,07 & $341.953 .344 .409,82$ \\
2015 & $46.433 .030,26$ & $28.993 .633 .471,42$ & $242.581 .904,74$ & $307.772 .433 .759,15$ & 0,01 & 0,07 & $337.055 .082 .165,57$ \\
2016 & $45.821 .380,87$ & $29.230 .654 .510,52$ & $248.003 .088,49$ & $274.574 .078 .201,68$ & 0,02 & 0,08 & $304.098 .557 .181,56$ \\
2017 & $46.948 .435,31$ & $28.476 .238 .640,82$ & $271.963 .292,08$ & $294.305 .347 .654,81$ & 0,01 & 0,08 & $323.100 .498 .023,02$ \\
2018 & $45.994 .588,09$ & $30.266 .822 .891,63$ & $277.861 .523,13$ & $282.883 .594 .071,11$ & 0,01 & 0,09 & $313.474 .273 .073,96$ \\
2019 & $44.991 .000,00$ & $32.328 .465 .000,00$ & $304.789 .000,00$ & $275.683 .921 .000,00$ & 0,01 & 0,10 & $308.362 .166 .000,00$ \\
TGCA & $-0,22 \%$ a.a. & $14,05 \%$ a.a. & $11,84 \%$ a.a. & $8,81 \%$ a.a. & & $9,18 \%$ a.a. \\
\hline
\end{tabular}

Fonte: Brasil (2020c). Nota: O valor da taxa geométrica de crescimento anual de benefícios cedidos à agropecuária em conjunto com a agroindústria e aos demais setores refere-se ao período de 2003-2019, exceto para o do seguro rural e para o das isenções a imóveis rurais.

Portanto, nota-se que os subsídios tributários buscam privilegiar os demais setores da economia, mas não necessariamente a agropecuária. Isto condiz com os resultados de Regazzini \& Bacha (2012) de que o setor agropecuário exprime um superávit fiscal ao Governo Federal (ou seja, o Governo Federal arrecada mais tributos do que tem de gastos com a agropecuária).

\section{Considerações Finais}

Este trabalho teve por finalidade analisar as subvenções federais (tributárias, financeiras e creditícias) concedidas à agropecuária no período de 2003 a 2019, utilizando-se de dados da Secretaria de Avaliação, Planejamento, Energia e Loteria (SECAP) do Ministério da Economia. 
Diversamente dos demais trabalhos que examinam gastos e tributação na agropecuária, o presente artigo foca apenas em uma categoria de gastos do Governo Federal (as subvenções) e as desagrega em tributárias, financeiras e creditícias. Essas subvenções são, por sua vez, separadas nas concedidas à agropecuária e aos demais setores, e as primeiras são, por sua vez, no que for possível, separadas nas concedidas aos agricultores familiares versus aos não familiares e por tipo de política agrícola (crédito rural, preços mínimos e seguro rural).

As principais constatações do artigo são: (1) o setor agropecuário tem recebido relativamente (a outros setores e em relação a seu PIB), nas duas primeiras décadas do século XXI, menos subvenções do Governo Federal; (2) enquanto para a economia brasileira como um todo há predominância de subvenções tributárias, para a agropecuária há predominância de subvenções financeiras; (3) os programas de crédito rural são os que mais recebem as subvenções do Governo Federal; (4) dentro do crédito rural, a maior parcela das subvenções é dada à agricultura familiar, por via do PRONAF; (5) mas, dentro da política de preços mínimos, a maior parte das subvenções é dada a programas que atendem a agricultura não familiar.

Esses resultados estão coerentes com as mudanças feitas na política agrícola brasileira desde meados dos anos de 1990, quando foram instituídos novos programas de crédito rural, preços mínimos e seguro agrícola, em que o setor privado tem maior participação e há menor subvenção do Governo, ao mesmo tempo em que outros programas específicos foram criados para subvencionar a agropecuária familiar. Essa bipartição na orientação da política agrícola, e com influxos na política fiscal, refletem, de um lado, as forças dos distintos agentes (também chamados de atores) que influenciam a formulação de políticas agrícolas; e, de outro lado, a robusta orientação para o mercado (principalmente o externo) da produção agropecuária, o que Ihe permitiu ter maior financiamento do setor privado.

O presente trabalho, por ser uma pesquisa documental e explicativa, não testou modelos econométricos capazes de evidenciar relações de equilíbrio de longo prazo entre as subvenções tributárias, creditícias e financeiras e os valores de crédito rural, preços mínimos e apólices de seguro rural. À medida que os dados estiverem disponíveis para tal finalidade, futuros trabalhos, decerto, poderão realizar esta análise econométrica.

\section{Referências}

Bacha, C. J. C. (2018). Economia e Política Agrícola no Brasil. Campinas, SP: Alínea.

Banco Central do Brasil - BCB. (2020). Crédito rural. Recuperado em 07 de março de 2020, de https://www.bcb.gov.br/estabilidadefinanceira/creditorural

Betarelli Junior, A. A., Faria, W. R., \& Albuquerque, D. P. E. M. (2019). Crédito rural, tipos de financiamentos e efeitos econômicos: o caso dos recursos equalizáveis de juros para o investimento e custeio agropecuário no Brasil (2012). Planejamento e Políticas Públicas, (52), 111-147.

Brasil. (1992). Lei n. 8.427, de 27 de maio de 1992. Dispõe sobre a concessão de subvenção econômica nas operações de crédito rural. Diário Oficial [da] República Federativa do Brasil, Brasília. Recuperado em 25 de outubro de 2020, de https://www2.camara.leg.br/legin/fed/ lei/1992/lei-8427-27-maio-1992-362961-publicacaooriginal-1-pl.html

Brasil. Ministério da Agricultura, Pecuária e Abastecimento - MAPA. (2020a). Balança comercial. Brasília: MAPA. Recuperado em 10 de outubro de 2020, de https://www.gov.br/agricultura/ pt-br/assuntos/relacoes-internacionais/estatisticas-de-comercio-exterior 
Brasil. Ministério da Agricultura, Pecuária e Abastecimento - MAPA. (2020b). Programa de Seguro Rural: Limites e Percentuais de Subvenção. Recuperado em 20 de outubro de 2020, de https://www.gov.br/agricultura/pt-br/assuntos/riscos-seguro/seguro-rural/limitespercentuais-de-subvencao

Brasil. Ministério da Economia. Secretaria de Avaliação, Planejamento, Energia e Loteria. (2020c). $4^{\circ}$ Orçamento de Subsídios da União. Brasília: Ministério da Economia. Recuperado em 29 de abril de 2021, de https://www.gov.br/economia/pt-br/centrais-de-conteudo/publicacoes/ boletins/boletim-subsidios/arquivos/2020/osu-2020-final-em-09-07-2020-18h25.pdf

Cardoso, D. F. (2011). Efeitos da política de equalização da taxa de juros do crédito rural nas regiões brasileiras. (Dissertação de mestrado). Programa de Pós-graduação em Economia Aplicada, Universidade Federal de Viçosa, Viçosa.

Costa, A. C. (2018). Macroeconomia brasileira e seus desafios. In: R. Rodrigues (Org.), Agro é paz: análises e propostas para o Brasil alimentar o mundo (pp. 25-30). Piracicaba: ESALQ.

Dias, G. L. S., \& Amaral, C. M. (2001). Mudanças estruturais na agricultura brasileira, 1980-98 (Vol. 99; Série Desarrollo Productivo). Santiago, Chile: Cepal.

Gasques, J. G. (2017, abril). Nota sobre os gastos públicos na agricultura. Brasília: Ministério da Agricultura, Secretaria de Política Agrícola.

Gasques, J. G. (2021, julho 22). Nota sobre os gastos públicos na agricultura (Nota n 17-2021/ CGAPI/DCI/SPA/MAPA). Brasília: Ministério da Agricultura, Secretaria de Política Agrícola.

Gasques, J. G., \& Conceição, J. C. P. R. (2001). Financiamento da agricultura: experiências e propostas. In J. G. Gasques \& J. C. P. R. Conceição (Orgs.), Transformações da agricultura e políticas públicas (pp. 95-155). Brasília: Ipea.

Gasques, J. G., Verde, C. M. V., \& Bastos, E. T. (2010). Gastos públicos na agricultura: uma retrospectiva. Revista de Política Agrícola, 19(esp.), 74-92.

Gil, A. C. (2008). Métodos e técnicas de pesquisa social(6. ed.). São Paulo: Atlas.

Hermann, J. (2011). Auge e declínio do modelo de crescimento com endividamento: o II PND e a crise da dívida externa (1974-1984). In F. Giambiagi, A. Villela, L. Barros de Castro, \& J. Hermann (Orgs.), Economia Brasileira Contemporânea: 1945-2010 (pp. 73-96). Rio de Janeiro: Elsevier.

Instituto Brasileiro de Geografia e Estatística - IBGE. (2019). Levantamento Sistemático da Produção Agrícola: estatística da produção agrícola. Rio de Janeiro: IBGE. Recuperado em 10 de outubro de 2020, de https://biblioteca.ibge.gov.br/visualizacao/periodicos/2415/ epag_2019_dez.pdf

Lamounier, B. (1994). Determinantes Políticos da Política Agrícola: Um Estudo de Atores, Demandas e Mecanismos de Decisão (Estudos de Política Agrícola, n 9). Brasília: Ipea.

Macedo, L. O. B., Pacheco, A. B., \& Espírito Santo, É. S. (2013). A evolução do Programa de Subvenção do Prêmio do Seguro Rural: uma avaliação do período de 2006 a 2010. Indicadores Econômicos FEE, 4O(4), 99-112.

Mueller, C. C. (1983). A racionalidade, o poder e a formulação de políticas agrícolas no Brasil. Revista de Economia e Sociologia Rural, 21(2), 157-172.

Mueller, C. C. (2010). A política agrícola no Brasil: uma visão de longo prazo. Revista de Política Agrícola, 19(esp.), 9-23. 
Organisation for Economic Co-operation and Development - OECD. (2021). Agricultural support. Recuperado em 29 de abril de 2021, de https://data.oecd.org/agrpolicy/agricultural-support. $\mathrm{htm}$

Ozaki, V. A. (2006). Aspectos contratuais e performance atuarial do seguro de custeio agrícola. Revista Paranaense de Desenvolvimento, 109, 27-48.

Ozaki, V. A. (2007). O papel do seguro na gestão do risco agrícola e os empecilhos para o seu desenvolvimento. In Anais do Congresso da Sociedade Brasileira de Economia, Administração e Sociologia Rural (SOBER). Brasília: SOBER.

Regazzini, L. C., \& Bacha, C. J. C. (2012). Tributação e gastos federais na agropecuária brasileira. Revista de Política Agrícola, 21(3), 55-67.

Sabourin, E. P. (2007). Que política pública para a agricultura familiar no segundo governo Lula? Sociedade e Estado, 22(3), 715-751.

Santiago, M. M. D., \& Silva, V. (1999). A política de crédito rural brasileira e o endividamento do setor agrícola: antecedentes e desdobramentos recentes. Agricultura em São Paulo, 46(2), 47-69.

Santos, G. R., \& Freitas, R. E. (2017). Gasto público com a agricultura no Brasil: uma abordagem a partir de dados desagregados. Boletim Regional, Urbano e Ambiental, (17), 89-98. Recuperado em 25 de outubro de 2020, de http://repositorio.ipea.gov.br/bitstream/11058/8159/1/ BRU_n17_Gasto.pdf

Schedenffeldt, B. F., Lima, A. T., Levrero, G. R. R., Pinto, M. R., \& Montebello, A. E. S. (2021). Instrumentos privados de financiamento do agronegócio. Revista de Política Agrícola, 30(1), 70-84.

Schwantes, F., \& Bacha, C. J. C. (2019). Análise da formulação da política de garantia de preços mínimos no Brasil pela ótica da economia política. Nova Economia, 29(1), 161-192.

Teixeira, E. C., Miranda, M. H., \& Freitas, C. O. (2014). Políticas governamentais aplicadas ao agronegócio. Viçosa, MG: Editora da UFV.

Xavier, L. F. (2021). Recursos do orçamento público federal destinados ao meio rural: dinâmica das contas brasileiras entre 2000 e 2017. Revista de Economia e Sociologia Rural, 59(2), 1-20. Recuperado em 29 de abril de 2021, de https://www.scielo.br/j/resr/a/LVKskC4KQH JpYLqNvN5gQRG/?format=pdf\&lang=pt 